\title{
Lifecycle Optimization in the Refrigeration Industry: A literature review
}

\author{
Daniele Cerri, Rossella Luglietti, Paolo Rosa, Sergio Terzi \\ Department of Management, Economics and Industrial Engineering \\ Politecnico di Milano \\ Piazza Leonardo Da Vinci 32, 20133, Milano, Italy \\ daniele.cerri@polimi.it, rossella.luglietti@polimi.it, paolo1.rosa@polimi.it, sergio.terzi@polimi.it
}

\begin{abstract}
Magnetic cooling technology, originally developed by Small and Medium Enterprises (SMEs) some years ago, is currently under evaluation by different global appliance manufacturers. Their intent is the direct application of it in the domestic refrigeration market for the construction of future products. - The aim of this paper is to conduct a literature review of current lifecycle optimization methods adopted in the refrigeration industry and, if possible, to evaluate their use on magnetic cooling technology, although the current public available information is limited. To this aim, an analysis of different methodologies will be presented and evaluated from a managerial point of view. These findings will be useful for the requirements definition of a subsequent simulation toolbox.
\end{abstract}

Keywords - Lifecycle Optimization, Lifecycle Assessment, Lifecycle Costs, Refrigeration Industry, Literature Review

\section{INTRODUCTION}

Refrigerators are one of the main sources of energy consumption around the world. Their use is continuous, $24 \mathrm{~h} / 7$, 365 days per year. During the last years, there was an increase in regulations around the world related to new energy efficiency standards, trying to reduce the overall consumption of energy of refrigerators. Global appliance manufacturers had to adopt periodically more and more severe regulations before the launch of new products into the market. For this reason, multinational companies involved in the production of refrigeration systems started to assess actively the potentials of innovative technologies. One of the possible solutions to reduce energy consumptions in refrigeration is represented by magnetic cooling technology at room temperature. Magnetic cooling systems can be intrinsically more efficient at low cooling power, if compared to the well-known gas compression based technology, and could theoretically simplify the entire system by reducing the overall environmental impact. However, magnetic cooling technology is still under development and there are very limited information about its costs and environmental impact. Furthermore, being also magnetic cooling engine production process under development, there is not yet the possibility to assess reliably it in terms of costs and environmental impact. In fact, magnetic cooling technology exploits metallic alloys of which composition is not always known with precision. However, high-volume marketable products require the public availability of all these information. The aim of the present paper is to present the literature review of current lifecycle optimization methods adopted, so far, in the refrigeration industry, trying to evidence current trade-offs. The paper is organized as follows. The relation to the existing theories and works are described in Section 2. Section 3 presents the research approach. Section 4 shows an overview of the main findings. Section 5 presents some concluding remarks and future perspectives.

\section{RELATION TO EXISTING THEORIES AND WORKS}

This section has the aim to describe a series of important points coming from the literature related to three different methodologies, or Life Cycle Optimization (LCO), Life Cycle Assessment (LCA), and Life Cycle Costing (LCC) selected for the sustainability assessment of the refrigeration industry.

\section{Life Cycle Optimization}

LCO is an emerging reference term for addressing the issues of evaluating the overall impacts that a proposed design solution could register during its life, once launched in the market. These impacts are generally defined both in terms of costs (accrued by a customer using a product) and environmental effects (e.g. potential polluting conditions or contaminating factors, but also reusable items and recyclable materials), and evaluated through well-known lifecycleoriented techniques, as LCC and LCA. First examples of LCO practices applied in the refrigeration sector appeared at the beginning of 2000 (e.g. [21]; [15]; [18]), when products and processes sustainability began to increase its importance in the industrial context. Since the year 2000, many kinds of LCO methods, models and simulation software tools have been developed and described by the scientific literature in 11 papers. They can be approximately grouped into two main categories depending on their focus:

- $\quad$ LCA and LCC optimization models;

- $\quad$ Product design and logistic networks optimization models.

The first group (comprising 7 out of 11 papers) is focused on the minimization of lifecycle costs and environmental impacts from a manufacturer or customer perspective, given a 
specific product definition. The second group (comprising 3 out of 11 papers) is focused on the optimization of product features and performances (only from the manufacturer perspective), given a set of pre-defined economic and environmental reference parameters. Only in one case (e.g. [4]) there is a contemporary focus on LCA/LCC and logistic networks optimization. Table I reports the LCO literature analysis results distinguished by optimization focus.

From a purely methodological point of view, there are many types of optimization processes, varying from author to author. The majority of them (6 out of 11 papers) use dynamic ([15]; [19]; [4]; [6]) or non-linear ([9]; [3]) programming based on multi-objective functions as optimization procedure. The rest of them (5 out of 11 papers) ([21]; [12]; [31]) prefer to reduce the computational impact of the optimization process by using Genetic Algorithms (GAs) coupled with multi-objective functions (subsequently evolved into Group Genetic Algorithms - GGAs, by enhancing the lifecycle perspective) or analytical models ([5]; [28]). Table II reports the LCO literature analysis results distinguished by optimization method.

What emerges from the previous tables is the lack of a standard methodology to assess the lifecycle optimization of a fridge. There are many different methods described by the literature, but none of them seems to consider the whole lifecycle, but a limited part of it. Furthermore, some methods (e.g. GAs) seem too complex to be adopted by industrial companies.

TABLE I. OPTIMIZATION FOCUS

\begin{tabular}{|l|c|c|c|c|c|c|c|c|c|c|c|}
\hline \multirow{2}{*}{ Focus } & \multicolumn{10}{|c|}{ Reference papers } \\
\cline { 2 - 12 } & {$[28]$} & {$[21]$} & {$[12]$} & {$[9]$} & {$[4]$} & {$[15]$} & {$[3]$} & {$[5]$} & {$[19]$} & {$[6]$} & {$[31]$} \\
\hline LCA/LCC & $\mathrm{x}$ & & & $\mathrm{x}$ & $\mathrm{x}$ & $\mathrm{x}$ & $\mathrm{x}$ & $\mathrm{X}$ & $\mathrm{x}$ & $\mathrm{x}$ & \\
\hline $\begin{array}{l}\text { Product design } \\
\text { \& logistic } \\
\text { network }\end{array}$ & & $\mathrm{x}$ & $\mathrm{x}$ & & $\mathrm{x}$ & & & & & & $\mathrm{x}$ \\
\hline
\end{tabular}

TABLE II. OPTIMIZATION METHODS

\begin{tabular}{|l|c|c|c|c|c|c|c|c|c|c|c|}
\hline \multirow{2}{*}{ Method } & \multicolumn{70}{|c|}{ Reference papers } \\
\cline { 2 - 13 } & {$[28]$} & {$[21]$} & {$[12]$} & {$[9]$} & {$[4]$} & {$[15]$} & {$[3]$} & {$[5]$} & {$[19]$} & {$[6]$} & {$[31]$} \\
\hline Dynamic progr. & & & & & $\mathrm{x}$ & $\mathrm{x}$ & & & $\mathrm{x}$ & $\mathrm{x}$ & \\
\hline Non linear progr. & & & & $\mathrm{x}$ & & & $\mathrm{x}$ & & & & \\
\hline $\begin{array}{l}\text { Genetic } \\
\text { algorythms }\end{array}$ & & $\mathrm{x}$ & $\mathrm{x}$ & & & & & & & & $\mathrm{x}$ \\
\hline Analytical models & $\mathrm{x}$ & & & & & & & $\mathrm{x}$ & & & \\
\hline
\end{tabular}

Life Cycle Assessment

LCA (or its alternative, Dynamic Life Cycle Assessment DLCA) is the standard methodology for the definition of the potential overall environmental impacts of a certain product (e.g. [16]; [17]). In the refrigeration sector (as in others household appliances), LCA implies to consider a series of factors. At first level, it assesses the total amount of raw materials and energy consumed to produce, use and dispose / remanufacture / recycle a fridge ([12]; [14]; [29]; [2]; [31]). At second - and more detailed - level, it evaluates the amount of pollutants released by refrigerators, their toxicity level in terms of air, water and soil contamination, and human health risks ([9]; [8]). Some authors ([11]; [19]) take an integrated perspective, by considering both the previous views. Other experts extend the LCA boundary outside the company for different evaluation purposes:

- $\quad$ Reverse and closed-loop supply chains ([21]; [4]);

- $\quad$ Disposal pathways ([22]; [23]);

- $\quad$ Lifecycle scenarios ([20]; [10]; [6]).

Table III reports the LCA literature analysis (applied to refrigerators) results of Life Cycle Inventory (LCI) distinguished by three views, or Beginning of Life (BoL), Middle of Life (MoL), and End of Life (EoL). Results show that $\mathrm{BoL}$ and $\mathrm{MoL}$ views are well stressed by the literature, even if not all papers discuss the entire set of indexes. Instead, the EoL view is described into detail only by some papers (usually under the form of disposal impacts) and, generally, is seen as a topic more related to manufacturers than customers. Table IV shows the typical impact categories discovered during the literature review in the refrigeration sector. Many papers, which analysed the Life Cycle Impact Assessment (LCIA) considered all typical impact categories, without using single score characterization methods. In general, the two tables show that some papers ended the analysis at LCI level, without evaluating Impact Assessment. This is possible when the analysis is focused on evaluating the only energy consumption or resources depletion.

A particular example of LCA application in the refrigeration industry is represented by magnetic cooling system refrigerators. The work of [24] is one of the few evaluating the environmental impacts of magnetic refrigerators, comparing them with data coming from the same analysis on a traditional vapour compression system. Results show that magnetic refrigeration has a higher environmental impact than vapour compression technology, mainly because of the intensive use of critical raw materials (e.g. rare earths like Gadolinium, Neodymium, and Dysprosium) during the production of permanent magnets. In fact, a $100 \%$ landfill of the magnetic materials is assumed, which reflects the current end of life path of rare earths ([7]). 
TABLE III. LIFE CYCLE INVENTORY FOCUS

\begin{tabular}{|c|c|c|c|c|c|c|c|c|c|c|c|c|c|c|c|c|c|c|c|c|c|}
\hline \multirow{2}{*}{ View } & \multirow{2}{*}{ Index } & \multicolumn{20}{|c|}{ Reference papers } \\
\hline & & [2] & {$[8]$} & [11] & [21] & {$[12]$} & [9] & [10] & [4] & [29] & [15] & [24] & [3] & [5] & [19] & [6] & [14] & {$[31]$} & [30] & [23] & [22] \\
\hline \multirow{3}{*}{ BoL } & $\begin{array}{l}\text { Raw mat. } \\
\text { extr. }\end{array}$ & $\mathrm{x}$ & & & $\mathrm{x}$ & & $\mathrm{x}$ & $\mathrm{x}$ & $\mathrm{x}$ & & & $\mathrm{x}$ & $\mathrm{x}$ & & $\mathrm{x}$ & $\mathrm{x}$ & & $\mathrm{x}$ & $\mathrm{x}$ & & \\
\hline & $\begin{array}{l}\text { Manuf. } \\
\text { energy cons. }\end{array}$ & $\mathrm{x}$ & $\mathrm{x}$ & $\mathrm{x}$ & $\mathrm{x}$ & $\mathrm{x}$ & $\mathrm{x}$ & & $\mathrm{x}$ & $\mathrm{X}$ & $\mathrm{x}$ & $\mathrm{x}$ & $\mathrm{x}$ & $\mathrm{x}$ & $\mathrm{x}$ & $\mathrm{x}$ & $x$ & $\mathrm{x}$ & $\mathrm{x}$ & $\mathrm{x}$ & $\mathrm{x}$ \\
\hline & $\begin{array}{l}\text { Transport. } \\
\text { impact }\end{array}$ & $\mathrm{x}$ & & & & & & & & & & $\mathrm{x}$ & & & & & & & & & \\
\hline MoL & $\begin{array}{l}\text { Use energy } \\
\text { cons. }\end{array}$ & $\mathrm{x}$ & $\mathrm{x}$ & $\mathrm{x}$ & & $\mathrm{x}$ & & & $\mathrm{x}$ & $\mathrm{X}$ & $\mathrm{x}$ & $\mathrm{x}$ & & $\mathrm{x}$ & $\mathrm{X}$ & $\mathrm{x}$ & $\mathrm{x}$ & $\mathrm{x}$ & & $\mathrm{x}$ & $\mathrm{x}$ \\
\hline \multirow{5}{*}{ EoL } & $\begin{array}{l}\text { Rev./closed } \\
\text { loop SC } \\
\text { impact }\end{array}$ & & & & $\mathrm{x}$ & & & & $\mathrm{x}$ & & & & & & & & & & & & \\
\hline & Reuse impact & & & & & & & & & & & & & $\mathrm{x}$ & & & & $\mathrm{x}$ & & & \\
\hline & $\begin{array}{l}\text { Reman. } \\
\text { Impact }\end{array}$ & $\mathrm{x}$ & & & & & & & & & & & & $\mathrm{x}$ & & & & & & & \\
\hline & $\begin{array}{l}\text { Recycling } \\
\text { impact }\end{array}$ & $\mathrm{x}$ & & & & & & & & & & & & $\mathrm{x}$ & & & & $\mathrm{x}$ & & & \\
\hline & $\begin{array}{l}\text { Disposal } \\
\text { impact }\end{array}$ & $\mathrm{x}$ & & & $\mathrm{x}$ & $\mathrm{x}$ & & & & $\mathrm{X}$ & & $\mathrm{x}$ & & $\mathrm{x}$ & $\mathrm{X}$ & $\mathrm{x}$ & $\mathrm{x}$ & & & $\mathrm{x}$ & $\mathrm{x}$ \\
\hline
\end{tabular}

TABLE IV. LIFE CYCLE IMPACT ASSESSMENT FoCUS

\begin{tabular}{|c|c|c|c|c|c|c|c|c|c|c|c|c|c|c|c|c|c|c|c|c|}
\hline \multirow{2}{*}{ Index } & \multicolumn{20}{|c|}{ Reference papers } \\
\hline & [2] & [8] & [11] & [21] & [12] & [9] & {$[10]$} & [4] & [29] & {$[15]$} & [24] & [3] & [5] & [19] & [6] & [14] & [31] & [30] & [23] & [22] \\
\hline $\begin{array}{l}\text { Climate } \\
\text { change }\end{array}$ & & $\mathrm{x}$ & $\mathrm{x}$ & & & $\mathrm{x}$ & & $\mathrm{x}$ & & & $\mathrm{x}$ & $\mathrm{x}$ & & & $\mathrm{x}$ & & & & & $\mathrm{x}$ \\
\hline Ozone depl. & & $\mathrm{x}$ & $\mathrm{x}$ & & & $\mathrm{x}$ & & $\mathrm{x}$ & & & $\mathrm{x}$ & $\mathrm{x}$ & & & $\mathrm{x}$ & & & & & $\mathrm{x}$ \\
\hline $\begin{array}{l}\text { Human } \\
\text { toxicity }\end{array}$ & & $\mathrm{x}$ & $\mathrm{x}$ & & & $\mathrm{x}$ & & $\mathrm{x}$ & & & $\mathrm{x}$ & $\mathrm{x}$ & & & & & & & & $\mathrm{x}$ \\
\hline $\begin{array}{l}\text { Photochem. } \\
\text { oxidation }\end{array}$ & & $\mathrm{x}$ & $\mathrm{x}$ & & & & & $\mathrm{x}$ & & & $\mathrm{x}$ & $\mathrm{x}$ & & & & & & & & $\mathrm{x}$ \\
\hline $\begin{array}{l}\text { Particulate } \\
\text { matter }\end{array}$ & & $\mathrm{x}$ & & & & & & $\mathrm{x}$ & & & $\mathrm{x}$ & $\mathrm{x}$ & & & & & & & & $\mathrm{x}$ \\
\hline $\begin{array}{l}\text { Ionizing } \\
\text { radiation }\end{array}$ & & $\mathrm{x}$ & $\mathrm{x}$ & & & $\mathrm{x}$ & & $\mathrm{x}$ & & & $\mathrm{x}$ & $\mathrm{x}$ & & & $\mathrm{x}$ & & & & & \\
\hline $\begin{array}{l}\text { Terrestrial } \\
\text { acidific. }\end{array}$ & & $\mathrm{x}$ & $\mathrm{x}$ & & & $\mathrm{x}$ & & $\mathrm{x}$ & & & $\mathrm{x}$ & $\mathrm{x}$ & & & & & & & & $\mathrm{x}$ \\
\hline $\begin{array}{l}\text { Freshwater } \\
\text { euthropic. }\end{array}$ & & $\mathrm{x}$ & $\mathrm{x}$ & & & $\mathrm{x}$ & & $\mathrm{x}$ & & & $\mathrm{x}$ & $\mathrm{x}$ & & & & & & & & $\mathrm{x}$ \\
\hline $\begin{array}{l}\text { Marine } \\
\text { eutrophic. }\end{array}$ & & $\mathrm{x}$ & $\mathrm{x}$ & & & $\mathrm{x}$ & & $\mathrm{x}$ & & & $\mathrm{x}$ & $\mathrm{x}$ & & & & & & & & $\mathrm{x}$ \\
\hline $\begin{array}{l}\text { Terrestrial } \\
\text { eco-tox. }\end{array}$ & & $\mathrm{x}$ & $\mathrm{x}$ & & & $\mathrm{x}$ & & $\mathrm{x}$ & & & $\mathrm{x}$ & $\mathrm{x}$ & & & & & & & & $\mathrm{x}$ \\
\hline $\begin{array}{l}\text { Freshwater } \\
\text { eco-tox. }\end{array}$ & & $\mathrm{x}$ & $\mathrm{x}$ & & & $\mathrm{x}$ & & $\mathrm{x}$ & & & $\mathrm{x}$ & $\mathrm{x}$ & & & & & & & & $\mathrm{x}$ \\
\hline $\begin{array}{l}\text { Marine eco- } \\
\text { tox. }\end{array}$ & & $\mathrm{x}$ & $\mathrm{x}$ & & & $\mathrm{x}$ & & $\mathrm{x}$ & & & $\mathrm{x}$ & $\mathrm{x}$ & & & & & & & & $\mathrm{x}$ \\
\hline $\begin{array}{l}\text { Agricultur. Ind } \\
\text { occup. }\end{array}$ & & & & & & $\mathrm{x}$ & & $\mathrm{x}$ & & & $\mathrm{x}$ & $\mathrm{x}$ & & & & & & & & $\mathrm{x}$ \\
\hline $\begin{array}{l}\text { Urban lnd. } \\
\text { occup. }\end{array}$ & & & & & & $\mathrm{x}$ & & $\mathrm{x}$ & & & $\mathrm{x}$ & $\mathrm{x}$ & & & & & & & & $\mathrm{x}$ \\
\hline $\begin{array}{l}\text { Natural lnd. } \\
\text { transf. }\end{array}$ & & & & & & $\mathrm{x}$ & & $\mathrm{x}$ & & & $\mathrm{x}$ & $\mathrm{x}$ & & & & & & & & $\mathrm{x}$ \\
\hline Water deplet. & & & & & & & & $\mathrm{x}$ & & & $\mathrm{x}$ & $\mathrm{x}$ & & & & & & & & \\
\hline Metal deplet. & & & & & & $\mathrm{x}$ & & $\mathrm{x}$ & & & $\mathrm{x}$ & $\mathrm{x}$ & & & & & & & & $\mathrm{x}$ \\
\hline Fossil deplet. & & & & & & $\mathrm{x}$ & & $\mathrm{x}$ & & & $\mathrm{x}$ & $\mathrm{x}$ & & & & & & & & $\mathrm{x}$ \\
\hline None & $\mathrm{x}$ & & & $\mathrm{x}$ & $\mathrm{x}$ & & $\mathrm{x}$ & & $\mathrm{x}$ & $\mathrm{x}$ & & & $\mathrm{x}$ & $\mathrm{x}$ & & $\mathrm{x}$ & $\mathrm{x}$ & $\mathrm{x}$ & $\mathrm{x}$ & \\
\hline
\end{tabular}

However, there are ongoing works studying methods and challenges of recycling them. Among the actors involved in this field, the experts of the European rare earths resource efficiency and recycling working group, as a part of the European Rare Earths Competency Network, can be mentioned. Again, other experts (e.g. [27]) reviewed the proposed technologies and challenges to improve the current situation of recycling rare earth materials and proposed a plan for implementing their recycling. By considering the potential in recovery of magnetic materials, $90 \%$ in reuse of magnetic materials could be possible, but separating rare earth metals from alloys to recycle them is an energy-intensive and complex process. By considering these new research streams, an overall environmental impact reduction it is desirable to occur in the near future and magnetic refrigerators could really become a sustainable choice. 


\section{Life Cycle Costing}

Several magnetic cooling devices at room temperature have been developed at laboratory scale, and those designs are not yet realistically close to the performance, reliability, and cost of vapour compression based engine ([1]; [25]). Therefore, it is of outmost importance to understand how the total cost of cooling varies with the device configuration, refrigerant properties and operating conditions. Up to now, there are very few significant publications in this direction (e.g. [1]) presenting an optimization analysis, with the objective of estimating the minimum mass and cost of a magnetic refrigerator. However, the study conclusions are based only on capital cost minimization. In recent publications ([29]; [26]; [6]; [25]; [3]) experts linked the device configuration to its performances (a similar thing was done already in 1996 by [30], but with the aim to assess the relation between environmental impacts and performances, with a secondary role of costs). Therefore, it is only possible to determine both the production cost and use cost together, by quantifying the total cost of cooling for a given application. However, also in this case, total costs refer only to production or use phases ([20]), without having a whole lifecycle perspective. Few works ([21]; [5]; [31]) tries to analyse a wider set of lifecycle phases, including not only production, but also use and disposal (by considering reverse and closedloop supply chains costs). Table V reports the LCC literature analysis (applied to refrigerators) results distinguished by three (BoL, MoL and EoL) views. As it can be seen, BoL and MoL views are well outlined by the literature, even if almost half of papers focus on materials/components purchase and use energy costs. Instead, the EoL view is described into detail only by few papers.

The literature analysis of LCC shows that the experts focused their attention to the improvement of costs incurred by manufacturers and customers during the $\mathrm{BoL}$ and $\mathrm{MoL}$ phases. In detail, the most cited LCC indexes are represented by raw materials/components cost, manufacturing cost and use energy cost. EoL costs are only partially analysed by the literature and there are very few papers considering their improvement.

\section{RESEARCH APPROACH}

A systematic review of the literature was implemented, by focusing on a particular research question, here represented by refrigeration systems. Scientific papers, selected through the most popular scientific works search engines (e.g. Google ${ }^{\mathrm{TM}}$ Scholar, Sage ${ }^{\mathrm{TM}}$, Science Direct ${ }^{\mathrm{TM}}$, Springer ${ }^{\mathrm{TM}}$, Taylor\&Francis ${ }^{\mathrm{TM}}$ Online and Wiley ${ }^{\mathrm{TM}}$ Online Libraries), and published from 2000 up to 2014, were analysed. The keyword "refrigeration" was combined with different terms (e.g. magnetic, technology, optimization, lifecycle, analysis, economics, environmental impacts, or a mix of them) researched in titles, abstracts and keywords of papers.

Fig. 1 displays the results of the search process, both in terms of number of papers per year and publication trend. The total amount of papers (46) reveals the limited attention devoted to this topic (from 2000 up to the end of 2014) by the experts, especially on magnetic refrigeration. Papers consist in 30 publications in scientific journals with impact factor, 3 in scientific journals without impact factor, 8 in proceedings of scientific conferences, 4 scientific reports, and 1 industrial report.

The nationality of the papers' first author indicates USA as the major contributor, with 15 papers $(32.6 \%)$, followed by China (10.9\%), Brazil, France, and Japan (6.5\% each) - see Fig. 2.

There are several perspectives from which the refrigeration industry was approached. In macro topic terms, the lifecycle optimization perspective is the most discussed in the literature (30.4\%), followed by performance improvement $(21.7 \%)$, LCA (15.2\%), materials selection and other issues $(10.9 \%$ each), design optimization (8.9\%), and LCC (2.2\%) - see Fig. 3.

The analysis highlighted the multidisciplinarity of the topic. For this reason, journals pertain to various research fields and scientific areas. However, it is possible to identify subsets of journals with impact factor having the most significant number of contributions ( $65.2 \%$ of the total). Fig. 4 shows the top five journals, accounting for 23 papers $(50.0 \%$ of the total), with the International Journal of Refrigeration occupying the first position.

Finally, the research methodology ends with the papers classification by detailed topics. It is important to evidence that, in the $76.1 \%$ of cases, papers do not look at magnetic refrigeration. Furthermore, in the $97.8 \%$ of cases, papers do not look at lifecycle optimization for magnetic refrigeration see Fig. 5

This situation underlines the scarce interest of the international literature (dedicated to LCC, LCA and LCO studies) about the magnetic refrigeration, even if many experts (e.g. [1]; [24]; [25]) push on the need to think about this new type of refrigeration technology to reach the sought energy efficiency standards. 
TABLE V. LIFE CyCLE COSTING Focus

\begin{tabular}{|c|c|c|c|c|c|c|c|c|c|c|c|c|c|c|c|c|c|}
\hline \multirow{2}{*}{ View } & \multirow{2}{*}{ Index } & \multicolumn{16}{|c|}{ Reference papers } \\
\hline & & [2] & [28] & [21] & [25] & [12] & [1] & [4] & [29] & [15] & [3] & [5] & [19] & [6] & [31] & [30] & [23] \\
\hline \multirow{6}{*}{ BoL } & Process instalment costs & & & $\mathrm{x}$ & & & & & & & & & & & & & \\
\hline & Manufacturing energy costs & $\mathrm{x}$ & & $\mathrm{x}$ & & & & $\mathrm{x}$ & & & & $\mathrm{x}$ & & & $\mathrm{x}$ & $\mathrm{x}$ & $\mathrm{x}$ \\
\hline & Raw materials/components costs & & $\mathrm{x}$ & $\mathrm{x}$ & $\mathrm{x}$ & $\mathrm{x}$ & $\mathrm{X}$ & $\mathrm{x}$ & & & & $\mathrm{x}$ & & & $\mathrm{x}$ & & $\mathrm{x}$ \\
\hline & Labor costs & & & & & & & & & & & $\mathrm{x}$ & & & & & $\mathrm{x}$ \\
\hline & Transportation costs & & & $\mathrm{x}$ & & & & & & & & & & & & & \\
\hline & Purchase costs & & & & & & & & $\mathrm{x}$ & $\mathrm{x}$ & $\mathrm{x}$ & & $\mathrm{x}$ & $\mathrm{x}$ & & & \\
\hline \multirow{3}{*}{ MoL } & Installation costs & & & & & & & & & & & & & $\mathrm{x}$ & & & \\
\hline & Use energy costs & $\mathrm{x}$ & $\mathrm{x}$ & & $\mathrm{x}$ & $\mathrm{x}$ & & & $\mathrm{x}$ & $\mathrm{x}$ & $\mathrm{x}$ & $\mathrm{x}$ & $\mathrm{x}$ & $\mathrm{x}$ & $\mathrm{x}$ & $\mathrm{x}$ & $\mathrm{x}$ \\
\hline & Maintenance costs & & & & & & & & $\mathrm{x}$ & & $\mathrm{x}$ & $\mathrm{x}$ & & $\mathrm{x}$ & & & \\
\hline \multirow{5}{*}{ EoL } & Reverse/closed-loop SC costs & & & $\mathrm{x}$ & & & & & & & & & & & $\mathrm{x}$ & & \\
\hline & Reuse costs & & & & & & & & & & & $\mathrm{x}$ & & & & & \\
\hline & Remanufacturing costs & $\mathrm{x}$ & & & & & & & & & & $\mathrm{x}$ & & & & & \\
\hline & Recycling costs & & & & & & & & & & & $\mathrm{x}$ & & & & & \\
\hline & Disposal costs & & & $\mathrm{x}$ & & & & & & $\mathrm{x}$ & & $\mathrm{x}$ & & & $\mathrm{x}$ & & $\mathrm{x}$ \\
\hline
\end{tabular}

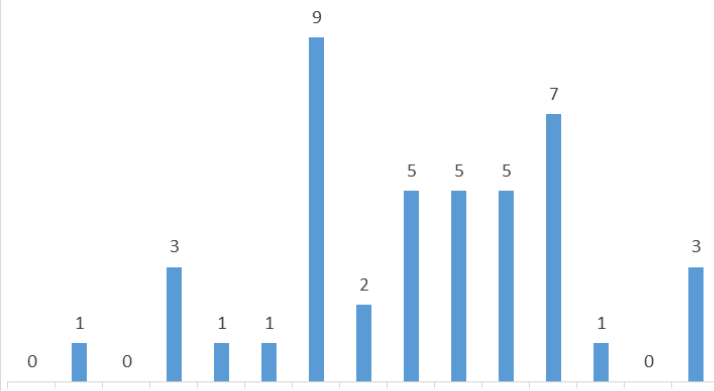

200020012002200320042005200620072008200920102011201220132014

Fig. 1. Historical series of published papers

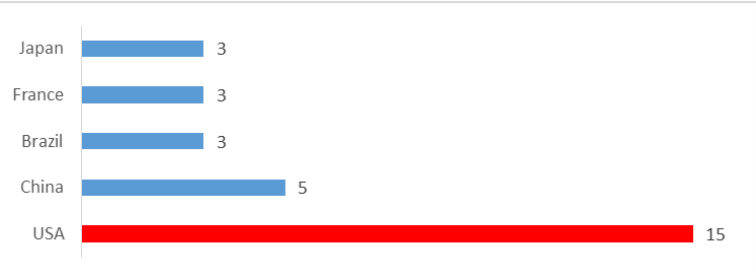

Fig. 2. Top five publishing countries

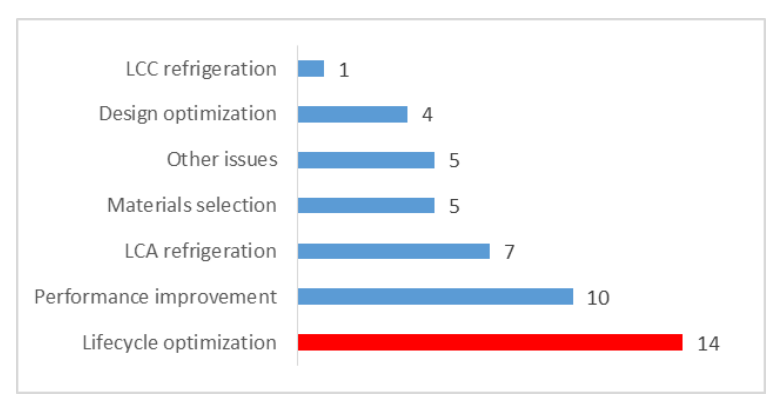

Fig. 3. Refrigeration industry macro research areas

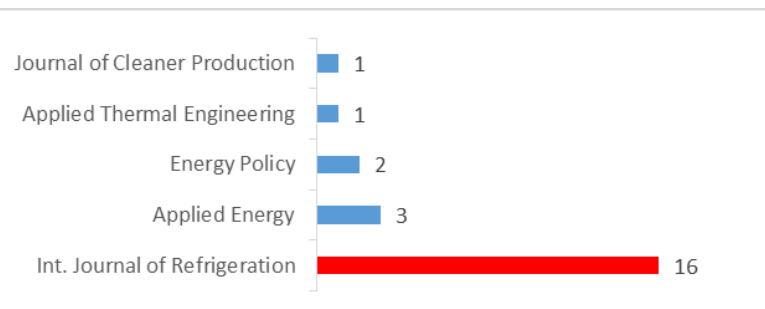

Fig. 4. Top five journals per number of publications

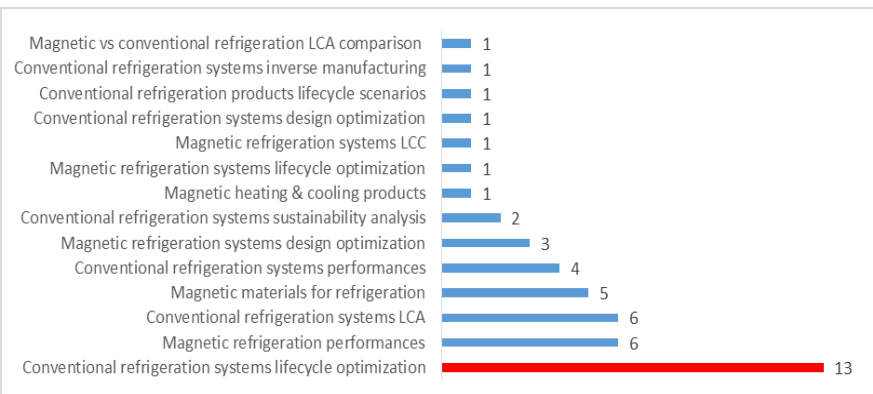

Fig. 5. Refrigeration industry detailed research areas

\section{FINDINGS}

The information given by the previous section allow in clarifying which are the current managerial weaknesses (in LCC, LCA and LCO terms) of magnetic refrigeration, and of the entire refrigeration industry. The present section will summarize them, trying to translate information in practical input for global appliance manufacturers.

The LCO literature shows a clear focus on the optimization of two distinct areas. From one hand, the authors tried to optimize performances, given a pre-defined set of target costs (e.g. investment and operational ones) and an overall environmental impact (e.g. in terms of $\mathrm{CO}_{2}$ emissions or energy consumption). From an opposite hand, the experts wanted to optimize costs and environmental impacts, given a pre-established set of product performances, features or components. However, both the first and the second views seem to be poorly focused on the sustainability assessment of products, but on the compliance with limits imposed by some 
business units within the company. Hence, it is evident the need to support designers with new optimization tools with a better perspective on lifecycle and sustainability issues.

From the LCA side, the literature review showed a great focus on $\mathrm{BoL}$ and $\mathrm{MoL}$ views. Hence, there is a need to extend the environmental analysis to EoL phase, by considering raw materials extraction (especially rare earths) and production processes. An energy mix evaluation is needed to evaluate the effect of different energy mix used in Europe and in the others countries (i.e. United States, China) on sustainability results. The product lifecycle flow has to be analysed by comparing the two refrigeration technologies (the gas compression based and the magnetic based ones) in terms of impact categories, and a standard set of indexes has to be adequately defined.

From the LCC side, what emerges from the previous literature analysis is a strong orientation on the assessment of costs accrued by customers (e.g. purchase and use energy costs) and manufacturers (e.g. raw materials/components and manufacturing energy costs). Instead, the EoL point of view is partially considered by the experts during their calculations. This implies a better understanding by manufacturers of the LCC methodology, and a better application of it on the whole supply chain (not only on a single part of it). This context demonstrates that, especially in the design phase, there is the need to consider a wider lifecycle perspective when calculating the economic sustainability of a product, without taking into consideration only some traditional cost indexes, but also the ones pertaining to the EoL phase.

From the EoL point of view, the experts (e.g. [24]) pointed out some doubts about the real sustainability of magnetic cooling technologies. In fact, the production of magnets implies the use of great amounts of rare earths, the group of raw materials re-known by the European Community and the United Nations Raw Materials Commission as the most critical in terms of environmental impact and supply risks. In fact, their extraction requires a great amount of energy and the percentage embedded in minerals ores is very low. In addition, the $97 \%$ of rare earth mines is located in China, one of the most protectionist nations in terms of raw materials. Given all these information, it could be interesting to analyse different scenarios characterized by different EoL strategies. For example, it should be useful to think about a possible reuse of EoL magnets into new domestic appliances. In this way, the environmental impact of magnetic technologies could be reduced and they could really become a sustainable solution.

\section{CONCLUSIONS}

The paper is focused on the assessment of the literature tackling the sustainability evaluation of the refrigeration industry, trying to extract significant information to use for the sustainability assessment of innovative magnetic refrigeration technologies. Emerging data show the presence of different lacks, both in optimization, environmental and economic assessment and product EoL management:

- From the optimization side, the focus is clearly inhomogeneous. From one hand, the authors try to optimize performances, given a pre-defined set of target costs (e.g. purchase and operational ones) and an overall environmental impact (e.g. in terms of $\mathrm{CO}_{2}$ emissions or energy consumption). From an opposite hand, the experts want to optimize costs and environmental impacts, given a pre-established set of product performances, features or components. However, both the first and second views seem to be poorly focused on the sustainability assessment of products, but on the compliance with limits imposed by some business units within the company.

- From the environmental side, the literature shows a great focus on BoL and MoL phases. In general terms, materials and energy consumption are the two more addressed topics, followed by a list of environmental indexes that, typically, are assessed by LCA software tools. However, only some experts propose a more complete vision, by considering, in addition to the previous indexes, also the EoL view and reverse logistics or closed-loop supply chain issues.

- From the economic side, what emerges from the previous literature analysis is a strong orientation on the assessment of costs pertaining to $\mathrm{BoL}$ and $\mathrm{MoL}$ phases (e.g. materials/components and manufacturing energy costs for producers and purchase and use energy costs for customers). The EoL point of view is partially considered by the experts during their calculations.

- $\quad$ From an EoL management side, the experts highlight the massive use of critical raw materials, which could have an impact on the sustainability of magnetic cooling technology compared to gas compression based technology. Hence, the analysis of different scenarios characterized by different EoL strategies should be of outmost importance.

All these findings represent the first step of the EU ELICiT project. They will be of outmost importance during the definition of requirements for the implementation of a subsequent LCO Simulation Toolbox (LCO-ST) dedicated to the sustainability assessment of refrigeration systems. By following the LCO logic previously described, the LCO-ST will be composed by three different views:

- An overall perspective reporting the main sustainability indexes, and allowing the direct comparison with gas compression based systems;

- $\quad$ An environmental perspective reporting both LCI and LCIA views pertaining to the LCA method;

- An economic perspective reporting cost items pertaining to the LCC method.

The whole set of these views, represented through a userfriendly control panel reporting both graphical and numerical information and statistics, could offer a great support to designers during the sustainability assessment of new products, as for magnetic refrigeration. 


\section{ACKNOWLEDGMENTS}

This work was partly funded by the European Commission through the ELICiT Project (ENV-2013-603885, www.elicitproject.eu). In any case, the present work cannot be considered as an official position of the supporting organizations (EU Commission), but it reports just the point of view of the authors.

\section{REFERENCES}

[1] Bjørk, R., Smith, A., Bahl, C. R. H., and N. Pryds. "Determining the minimum mass and cost of a magnetic refrigerator." Int. J. Refrig., vol. 34(8), 2011, pp. 1805-1816.

[2] Boustani, A., Sahni, S., Graves, S. C., and T. G. Gutowski. "Appliance remanufacturing and life cycle energy and economic savings." In Sustainable Systems and Technology (ISSST), 2010 IEEE International Symposium on (pp. 1-6). IEEE, 2010.

[3] Brunet, R., Cortés, D., Guillén-Gosálbez, G., Jiménez, L., and D. Boer. "Minimization of the LCA impact of thermodynamic cycles using a combined simulation-optimization approach.” Appl. Therm. Eng., vol. 48, 2012, pp. 367-377.

[4] Cacherat, A., Lecocq, N., and G. Kremer. "LCA of a refrigerator: A case study to optimize product modular design for reducing environmental impact in a closed-looped supply chain." In International Congress on Life Cycle Assessment, Lille, France, 2011.

[5] Chung, W. H., Okudan, G., and R.A. Wysk. "Modular design to optimize product life cycle metrics in a closed-looped supply chain." In Industrial Engineering Research Conference, Reno (pp. 21-25), May, 2011.

[6] De Kleine, R. D., Keoleian, G. A., and J.C. Kelly. "Optimal replacement of residential air conditioning equipment to minimize energy, greenhouse gas emissions, and consumer cost in the US." Energ. Policy, vol. 39(6), 2011, pp. 3144-3153.

[7] Du, Xiaoyue, and T.E. Graedel. "Global rare earth in-use stocks in NdFeB permanent magnets." J. Ind. Ecol. Vol. 15(6), 2011, pp. 836-843.

[8] Elijošiūtè, E., and V. Varžinskas. "Application of Life Cycle Measures to Increase Efficiency of Domestic Cooling Appliances." Environ. Res. Eng. Manag., vol. 54(4), 2011, pp. 54-61.

[9] Gebreslassie, B. H., Guillén-Gosálbez, G., Jiménez, L., and D. Boer. "Design of environmentally conscious absorption cooling systems via multi-objective optimization and life cycle assessment." Appl. Energ., vol. 86(9), 2009, pp. 1712-1722.

[10] Gehin, A., Zwolinski, P., and D. Brissaud. "Integrated design of product lifecycles - The fridge case study.” CIRP J. Manuf. Scie. Technol., vol. 1(4), 2009, pp. 214-220.

[11] Gheewala, S.H., and P.H. Nielsen. "Beyond energy efficiencyapplication of LCA for integrated environmental assessment." In Second Regional Conference on Energy Technology towards a Clean Environment, Phuket, Thailand, February, 2003.

[12] Gholap, A.K., and J.A. Khan. "Design and multi-objective optimization of heat exchangers for refrigerators." Appl. Energ., vol. 84(12), 2007, pp. 1226-1239.
[13] Gschneidner Jr, K.A., and V.K. Pecharsky. "Thirty years of near room temperature magnetic cooling: Where we are today and future prospects." Int. J. Refrig., vol. 31(6), 2008, pp. 945-961.

[14] Hermes, C.J., Melo, C., Knabben, F.T., and J.M. Gonçalves. "Prediction of the energy consumption of household refrigerators and freezers via steady-state simulation." Appl. Energ., vol. 86(7), 2009, pp. 1311-1319.

[15] Horie, Y.A. "Life cycle optimization of household refrigerator-freezer replacement." 2004 Master of Science Thesis, University of Michigan

[16] ISO 14040. "Environmental management -- Life cycle assessment -Principles and framework" 2006.

[17] ISO 14044. "Environmental management -- Life cycle assessment -Requirements and guidelines" 2006

[18] Kawanami, T., Chiba, K., Sakurai, K., and M. Ikegawa. "Optimization of a magnetic refrigerator at room temperature for air cooling systems." Int. J. Refrig., vol. 29(8), 2006, pp. 1294-1301.

[19] Kim, H.C., Keoleian, G.A., and Y.A. Horie. "Optimal household refrigerator replacement policy for life cycle energy, greenhouse gas emissions, and cost." Energ. Policy, 34(15), 2006, pp. 2310-2323.

[20] Kimura, F. (1999, February). "Life cycle design for inverse manufacturing." In Environmentally Conscious Design and Inverse Manufacturing (EcoDesign'99), 1999 IEEE First International Symposium on (pp. 995-999). IEEE, 1999.

[21] Krikke, H., Bloemhof-Ruwaard, J., and L.N. Van Wassenhove. "Concurrent product and closed-loop supply chain design with an application to refrigerators." Int. J. Prod. Res., vol. 41(16), 2003, pp. 3689-3719.

[22] Kurczewski, P., Kasprzak, J., and A. Lewandowaska. "The way to life cycle management of refrigerators in Poland." In $3^{\text {rd }}$ International Conference on Life Cycle Management. From analysis to implementation, Zurich, Switzerland, 2007.

[23] Kurczewski, P., and K. Koper. "The Concept of Monitoring of LCM Results Based on Refrigerators Case Study." In Towards Life Cycle Sustainability Management (pp. 513-522). Springer Netherlands, 2011.

[24] Monfared, B., Furberg, R., and B. Palm. "Magnetic vs. vaporcompression household refrigerators: A preliminary comparative life cycle assessment." Int. J. Refrig, vol. 42, 2014, pp. 69-76.

[25] Rowe, A. "Configuration and performance analysis of magnetic refrigerators." Int. J. Refrig, vol. 34(1), 2011, pp. 168-177.

[26] Russek, S.L., and C.B. Zimm. "Potential for cost effective magnetocaloric air conditioning systems.” Int. J. Refrig, vol. 29(8), 2006, pp. 1366-1373.

[27] Schüler, D., Buchert, M., Liu, R., Dittrich, S., Merz, C. "Study on rare earths and their recycling." Öko-Institut eV Darmstadt (2011).

[28] Tura, A., and A. Rowe. "Concentric Halbach cylinder magnetic refrigerator cost optimization.” Int. J. Refrig, vol. 37, 2014, pp. 106-116.

[29] Vendrusculo, E.A., de Castilho Queiroz, G., Jannuzzi, G.D.M., da Silva Júnior, H.X., and J.A. Pomilio. "Life cycle cost analysis of energyefficiency design options for refrigerators in Brazil." Energ. Effic., vol. 2(3), 2009, pp. 271-286.

[30] Weaver, P. M., Ashby, M. F., Burgess, S., and N. Shibaike. "Selection of materials to reduce environmental impact: a case study on refrigerator insulation.” Mater. Des., vol. 17(1), 1996, pp. 11-17.

[31] Yu, S., Yang, Q., Tao, J., Tian, X., and F. Yin. "Product modular design incorporating life cycle issues-Group Genetic Algorithm (GGA) based method." J. Clean. Prod., vol. 19(9), 2011, pp. 1016-1032. 